\title{
Dietary Intake of Macro- and Micronutrients in Slovenian Adolescents: Comparison with Reference Values
}

\author{
Nataša Fidler Mis Helena Kobe Matevž Štimec \\ Department of Gastroenterology, Hepatology and Nutrition, University Children's Hospital, University Medical \\ Centre Ljubljana, Ljubljana, Slovenia
}

\section{Key Words}

Adolescents $\cdot$ Nutrition $\cdot$ Diet $\cdot$ Food frequency

questionnaire $\cdot$ Slovenia

\begin{abstract}
Background: Data on a nationally representative dietary intake in Central Europe is lacking. We investigated the diet of adolescents in Slovenia. Methods: Dietary habits were assessed using a food frequency questionnaire $(n=2,661)$, and present nutrition was assessed using a 3-day weighted dietary protocol $(n=197)$ for validation purposes. Dietary intake was calculated and compared with Central European [German (D), Austrian (A), and Swiss (CH); D-A-CH] recommendations and World Health Organization/Food and Agriculture Organization (WHO/FAO) recommendations. $\boldsymbol{R e}$ sults: Adolescents consumed exceeding reference intake values of free sugars (boys $16 \%$ of energy, girls 17\%), saturated fatty acids (SFA; $13 \%$ of energy), and sodium (boys $203 \%$, girls $210 \%$ of the WHO/FAO upper limit), but belowreference intake values of polyunsaturated fatty acids (PUFA; boys $5 \%$ of energy; girls $6 \%$ ), water (boys $1,786 \mathrm{ml} /$ day, girls $2,016 \mathrm{ml} /$ day), and fiber density (only girls $2.8 \mathrm{~g} / \mathrm{MJ}, \mathrm{p}<$ 0.001 ). Among micronutrients, below-reference intakes (\% of $\mathrm{D}-\mathrm{A}-\mathrm{CH}$ : boys and girls, respectively, $\mathrm{p}<0.05)$ were reported for folate (64 and $69 \%)$, fluoride (28 and 31\%), and calcium
\end{abstract}

\section{KARGER}

Fax +4161306 1234

E-Mail karger@karger.ch

www.karger.com
(C) 2012 S. Karger AG, Basel

0250-6807/12/0614-0305\$38.00/0

Accessible online at:

www.karger.com/anm
(91 and 97\%), as well as for vitamin D (20 and 20\%). Conclusions: The dietary habits of Slovenian adolescents are less than optimal. They are characterized by exceeding reference intake values of free sugars, salt, and SFA, and a below-reference intake of PUFA, water, and several micronutrients.

Copyright $\odot 2012$ S. Karger AG, Basel

\section{Introduction}

Adolescence is a period of rapid growth, body changes, and re-establishment of behaviors, including eating habits. Many factors impact adolescents' eating behaviors, including society, parents' eating patterns, eating away from home, and physiological requirements [1]. Poor nutrient supply, as well as the establishment of unhealthy eating habits, can have a permanent impact on health status [2]. Assessment of their food intake is needed to learn about the nutritional status of adolescents, though their specific dietary habits, such as snacking, eating away from home, and skipping meals, make this assessment more difficult than in other age groups [3]. There has been no representative data on the nutrient intake of Slovenian adolescents until now.

This study is part of a cross-sectional study of goiter prevalence and food intake in Slovenian adolescents 
$[4,5]$. We investigated dietary habits and present diet by means of food frequency questionnaires (FFQ) and with 3 -day weighted dietary protocols (3DP). We aimed to evaluate the dietary intake of Slovenian adolescents and compare it with relevant recommendations.

\section{Materials and Methods}

The investigation took place in 10 Slovenian regions during systematic medical examinations in health centers. All information gathered, procedures performed, and questionnaires were standardized. The study protocol was approved by the Ethics Committee of the Medical Faculty of the University of Ljubljana (No. 84/06/02). After an explanation of the study, written informed consent was obtained from the parents of the adolescents.

\section{Subjects}

A total of 2,813 Slovenian adolescents (10\% of adolescents entering high school), aged 14-17 years, were recruited. In order to include adolescents from all socioeconomic groups, they were selected from various high school educational programs. The adolescents from each region were consecutively recruited during medical examinations until the specific number, proportional to the number of inhabitants of that region, was reached. Of those recruited, 95\% agreed and completed an FFQ (2,661 = adolescents with FFQ) at regional health centers while waiting for their medical examination. Adolescents received oral instructions by trained nurses (a course was held prior to the study, at the University Children's Hospital in Ljubljana). Instructions were also written on the first page of the FFQ. The FFQ could be completed within $15 \mathrm{~min}$. We excluded adolescents who: (a) had $\geq 4$ invalid answers on the frequency of consumption (missing frequency, multiple marks for frequency) ( $\mathrm{n}=96 ; 4 \%$ of adolescents with FFQ); (b) were aged $>16$ years $(n=80 ; 3 \%$ of adolescents with FFQ) or $<15$ years $(n=207 ; 8 \%$ of adolescents with FFQ), or (c) reported an extremely high (more than $3 \mathrm{SD}$ above the mean) or extremely low energy intake (boys $<600 \mathrm{kcal} /$ day; girls $<500 \mathrm{kcal} /$ day; $\mathrm{n}=54 ; 2 \%$ of adolescents with FFQ), as it markedly deviated from the majority. Additionally, such extreme energy intakes could not represent an average energy intake during the whole year. Excluding these adolescents did not affect the conclusions of the study, as the mean values remained the same, but it did lower the SD. Thus 2,224 adolescents (83\% of adolescents with FFQ; 1,010 boys and 1,214 girls) aged 15-16 years were included in the analysis.

\section{Anthropometrical and Food Intake Data}

Anthropometrical measurements, height and weight, were taken by the medical personnel. A dietary history method was used for the evaluation of dietary habits during the previous year. We used the Harvard University FFQ developed by Willett [6] and also described by Thompson and Byers [7]. The FFQ was semiquantitative, comprising 82 food items. The questions referred to the daily, weekly, and monthly consumption of various foodstuffs or groups of foodstuffs ( 9 frequency categories of consumption from never or <once/month to a maximum of 6 or more times/ day). Foods and table salt were categorized into the following groups: (1) milk and milk products, (2) meat and meat products, (3) fish and fish products, (4) fats, (5) starch foods, (6) vegetables, (7) fruits and nuts, (8) beverages, and (9) salt [5].

The amounts of foodstuffs were estimated from the FFQ, based on portion sizes that were adjusted post hoc on the basis of calculated average portion sizes obtained from 3DP, separately for girls and boys. The 3DPs were carried out by a subgroup of 197 adolescents (adolescents with suspected goiter and their controls [4]). They received oral and written instructions on how to complete the 3DP. Of the 197 adolescents, 191 (97\%) correctly completed the 3DP. Missing recordings of consumption for 1 or more days ( $n=6$; $3 \%$ of the completed 3DP) was an exclusion criterion. Portion sizes in the FFQ of foods without natural units (e.g. meat, rice, pasta, potatoes) were replaced with average portion sizes from the 3DP, while portion sizes for foods with natural units (e.g. 1 apple, $2 \mathrm{dl}$ of milk) remained the same as in the original FFQ.

The FFQs were analyzed with nutrition software (Prodi 5.2 expert plus; Stuttgart, Germany) [8]. Values for the iodine content of table salts sold in Slovenia were added [5].

The absolute intake of energy and nutrients from foods, drinks, and table salt was calculated based on the frequency of consumption (from FFQ), portion size (from FFQ and 3DP), and energy and nutrient content of each food item. Energy was expressed as daily intake in kilocalories and megajoules. The nutrient intake was expressed in (micro)grams/day, while carbohydrate, protein, and fat intakes were also expressed as a percentage of the daily energy intakes. Free sugars were defined as all monosaccharides and disaccharides (e.g. glucose, fructose, sucrose) added to foods by the manufacturer, cook, or consumer, plus sugars naturally present in honey, syrups, and fruit juices [9].

\section{Comparison with the Reference Intake}

The dietary habits were compared with D-A-CH reference values [10], which are official in Slovenia [11]. Since the D-A-CH reference values do not define the maximum daily sodium and sugar intake [10], we compared the adolescents' intake with World Health Organization/Food and Agriculture Organization(WHO/ FAO) recommendations (population nutrient intake goal for: sodium, $<2 \mathrm{~g} /$ day, and free sugars, $<10 \%$ of the daily energy intake) [9], which have also been adopted in Slovenia.

\section{Statistical Analysis}

The normality of the distribution was checked with the Shapiro-Wilk and Kolmogorov-Smirnov tests. The data (most of the variables) were log transformed. Nutrient intakes were adjusted for energy intake using the residual method [12]. We used statistical weighting to standardize the results [13]. The t test and MannWhitney $U$ test were used to compare differences between genders. The Wilcoxon signed-rank test was used to compare nutrient intakes with the recommendations. To assess the correlations of energy and macronutrient intake to weight and BMI, Spearman's rank coefficients were calculated. Statistical analyses were performed with the Statistical Package for Social Sciences (SPSS version 16.0; Chicago, Ill., USA). Results are presented as means $\pm \mathrm{SD}$. The two-tailed significance level was 0.05 . 
Table 1. Intake of energy and macronutrients in Slovenian adolescents compared to the reference intake values [9, 10]

\begin{tabular}{|c|c|c|c|c|}
\hline & \multicolumn{2}{|c|}{ Slovenian adolescents } & \multicolumn{2}{|c|}{ Reference intake values ${ }^{\mathrm{a}, \mathrm{b}}$} \\
\hline Energy intake* ${ }^{*} \mathrm{kcal} /$ day & $3,043 \pm 1,642^{\#}$ & $2,312 \pm 1,220^{\#}$ & $3,100^{\mathrm{a}, \mathrm{c}}$ & $2,500^{\mathrm{a}, \mathrm{c}}$ \\
\hline Carbohydrates*, g/day & $370 \pm 55$ & $379 \pm 55$ & - & - \\
\hline$\% \mathrm{E}^{*}$ & $57 \pm 9$ & $58 \pm 8$ & $>50^{\mathrm{a}} / 55-75^{\mathrm{b}}$ & $>50^{\mathrm{a}} / 55-75^{\mathrm{b}}$ \\
\hline Free sugars ${ }^{*}, \mathrm{~g} /$ day & $103 \pm 56$ & $110 \pm 60$ & - & - \\
\hline$\% \mathrm{E}^{*}$ & $16 \pm 9^{\#}$ & $17 \pm 9^{\#}$ & $<10^{\mathrm{b}}$ & $<10^{\mathrm{b}}$ \\
\hline Starches ${ }^{*}, \mathrm{~g} /$ day & $193 \pm 61$ & $177 \pm 59$ & - & - \\
\hline$\% \mathrm{E}^{*}$ & $30 \pm 9$ & $27 \pm 9$ & - & - \\
\hline Fiber*, g/day & $28 \pm 9^{\#}$ & $31 \pm 11^{\#}$ & $>25^{\mathrm{b}}$ & $>25^{\mathrm{b}}$ \\
\hline$\% \mathrm{E}$ & $13 \pm 3^{\#}$ & $13 \pm 3^{\#}$ & $<10^{\mathrm{a}, \mathrm{b}}$ & $<10^{\mathrm{a}, \mathrm{b}}$ \\
\hline MUFA, g/day & $30 \pm 9$ & $29 \pm 10$ & - & - \\
\hline$\% \mathrm{E}$ & $10 \pm 3$ & $10 \pm 3$ & $\geq 10^{\mathrm{a}}$ & $\geq 10^{\mathrm{a}}$ \\
\hline PUFA, g/day & $16 \pm 6$ & $17 \pm 7$ & - & - \\
\hline$\% \mathrm{E}$ & $5 \pm 2^{\#}$ & $6 \pm 2^{\#}$ & $7-10^{\mathrm{a}} / 6-10^{\mathrm{b}}$ & $7-10^{\mathrm{a}} / 6-10^{\mathrm{b}}$ \\
\hline Cholesterol*, mg/day & $268 \pm 82^{\#}$ & $247 \pm 77^{\#}$ & $<300^{\mathrm{a}, \mathrm{b}}$ & $<300^{\mathrm{a}, \mathrm{b}}$ \\
\hline Protein*, g/day & $96 \pm 18^{\#}$ & $86 \pm 17^{\#}$ & $60^{\mathrm{a}}$ & $46^{\mathrm{a}}$ \\
\hline$\% \mathrm{E}^{*}$ & $15 \pm 3$ & $13 \pm 3$ & $10-15^{b}$ & $10-15^{b}$ \\
\hline Protein, g/kg body weight/day & $1.5 \pm 0.4^{\#}$ & $1.5 \pm 0.4^{\#}$ & $0.9^{\mathrm{a}}$ & $0.8^{\mathrm{a}}$ \\
\hline Water*, $\mathrm{ml} /$ day & $1,786 \pm 614^{\#}$ & $2,016 \pm 711^{\#}$ & $2,450^{\mathrm{a}}$ & $2,450^{\mathrm{a}}$ \\
\hline
\end{tabular}

Values are means \pm SD. Total sugars (all monosaccharides and disaccharides) are free sugars plus sugars naturally present in foods (e.g. lactose in milk, fructose in fruits). Free sugars are all monosaccharides and disaccharides added to foods by the manufacturer, cook, or consumer, plus sugars naturally present in honey, syrups, and fruit juices [9]. Water refers to the total water from beverages and solid foods. \% E = Percentage of total energy intake; $-=$ no recommendation $[9,10]$.

${ }^{*} \mathrm{p}<0.05$ between boys and girls; ${ }^{*} \mathrm{p}<0.05$ in comparison with the recommendations.

a $\mathrm{D}-\mathrm{A}-\mathrm{CH}$ recommendations for the age group of 15 to $<19$ years; values for sexes are common or separated [10].

${ }^{\mathrm{b}} \mathrm{WHO} / \mathrm{FAO}$ recommendations [9].

${ }^{c}$ Average daily energy requirements, calculated as (reference) the basal metabolic rate of individuals with a normal body weight multiplied by the physical activity level value 1.75 [10].

\section{Results}

\section{Anthropometrical Data}

The age and BMI of the adolescents (mean $\pm \mathrm{SD}$ ) was $15.6 \pm 0.4$ years and $21.4 \pm 3.4$, with no difference between boys and girls. Boys were on average $9.9 \mathrm{~cm}$ taller (boys vs. girls: $175.7 \pm 7.0$ vs. $165.8 \pm 6.0 \mathrm{~cm}, \mathrm{p}<0.001$ ) and $7.8 \mathrm{~kg}$ heavier than girls (boys vs. girls: $66.5 \pm 11.9$ vs. $58.7 \pm 10.0 \mathrm{~kg}, \mathrm{p}<0.001)$.

\section{Energy Intake}

Both boys and girls reported energy intakes below the $\mathrm{D}-\mathrm{A}-\mathrm{CH}$ reference values (98 and $92 \%$ of $\mathrm{D}-\mathrm{A}-\mathrm{CH}, \mathrm{p}<$
0.05) (table 1). The Spearman rank coefficients between energy and BMI were -0.093 in girls $(\mathrm{p}<0.01)$ and -0.049 in both genders $(\mathrm{p}<0.01)$. The Spearman rank coefficients between energy and body weight were -0.080 in girls $(\mathrm{p}<0.01)$ and 0.068 in both genders $(\mathrm{p}<0.01)$.

\section{Macronutrient Intake}

The proportion between main macronutrients was adequate, with a slightly low intake of fat (28 and 29\% in boys and girls, respectively).

Carbohydrates contributed 57 and 58\% of the energy intake in boys and girls, respectively. Boys ingested a higher proportion of energy from starches than did girls 


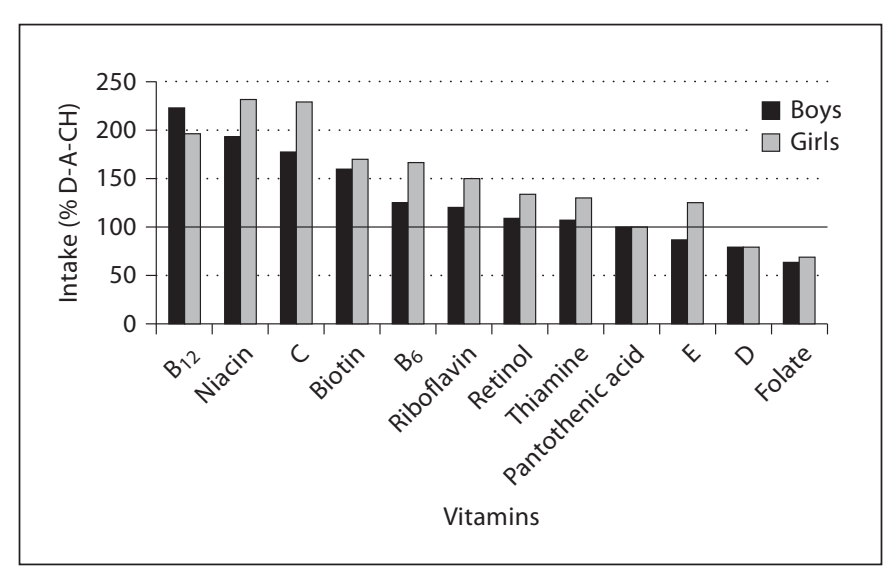

Fig. 1. Vitamins consumed by Slovenian adolescents compared to D-A-CH recommendations [10].

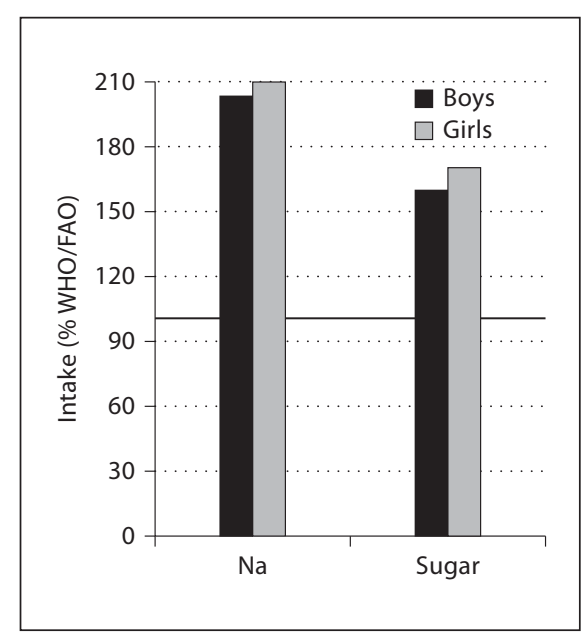

Fig. 3. Sodium and sugar consumed by Slovenian adolescents compared to the WHO/FAO upper recommended limit for intake [9].

( 30 vs. $27 \%$, p < 0.05). Both boys and girls had a high intake of free sugars (16 and $17 \%$ compared to the WHO/ FAO recommendation of $<10 \%)(\mathrm{p}<0.05)$. The absolute intake of fiber was above the recommendations in both genders.

Fat contributed less than $30 \%$ of the energy for both genders $(p<0.05)$ but had an inappropriate composition: too high an intake of saturated fatty acids [SFA; $13 \%$ in both genders vs. the recommended $<10 \%$ ( $p<0.05$ )], an appropriate intake of monounsaturated fatty acids (MUFA; 10\% in both genders vs. the recommended $\geq 10 \%$ ), and too low an intake of polyunsaturated fatty

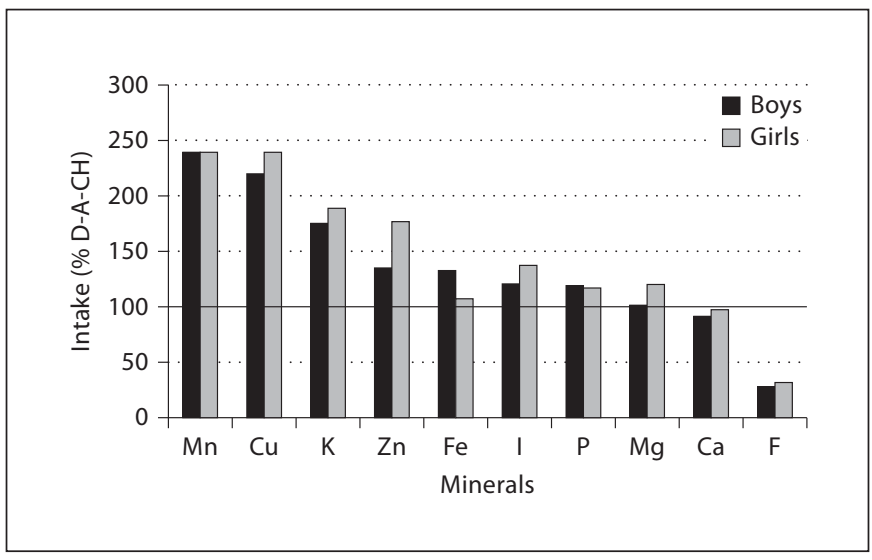

Fig. 2. Minerals and trace elements consumed by Slovenian adolescents compared to D-A-CH recommendations [10].

acids [PUFA; $5 \%$ in boys and $6 \%$ in girls vs. the $7-10 \%$ recommended by $\mathrm{D}-\mathrm{A}-\mathrm{CH}$ and the $6-10 \%$ recommended by the WHO/FAO $(\mathrm{p}<0.05)]$. The Spearman rank coefficient between body weight and fat intake was -0.059 in girls $(\mathrm{p}<0.05)$. Boys consumed more cholesterol than did girls $(p<0.05)$, although the intake in either gender did not exceed the upper limit of $300 \mathrm{mg} /$ day.

Protein contributed 15\% of the energy for boys and 13\% for girls. Boys consumed significantly more protein (absolute amount and energy percentage) than did girls ( $\mathrm{p}<$ 0.05 ). The Spearman rank coefficient between body weight and protein intake was 0.117 in both genders $(\mathrm{p}<0.01)$.

Water intake from beverages (calculated from the frequencies and amounts of beverages consumed based on the FFQ) and solid foods (calculated from consumed foods from the FFQ and the nutrition software [8]) was too low in both genders $(\mathrm{p}<0.05)$, with a higher water intake in girls $(\mathrm{p}<0.05)$.

\section{Micronutrient Intake}

The daily intake of micronutrients (12 vitamins, 6 minerals, and 6 trace elements) and the recommendations are shown in table 2 and figure 1 and 2 , and the intake of food groups is shown in table 3. Boys and girls consumed amounts below the reference intake values (\% D-A-CH; boys and girls, respectively) of two vitamins (folate: 64 and 69\%; vitamin D: 20 and 20\%, p < 0.05; fig. 1), one mineral (calcium: 91 and 97\%, p < 0.05; fig. 2), and one trace element (fluoride: 28 and $31 \%, \mathrm{p}<0.05$; fig. 2 ), and too high an amount of sodium (203 and $210 \%$ of the $\mathrm{WHO} / \mathrm{FAO}$ recommended upper limit, $\mathrm{p}<0.05$; fig. 3). 
Table 2. Intake of selected vitamins, minerals, and trace elements by Slovenian adolescents compared to the reference intake values $[10,33,41]$

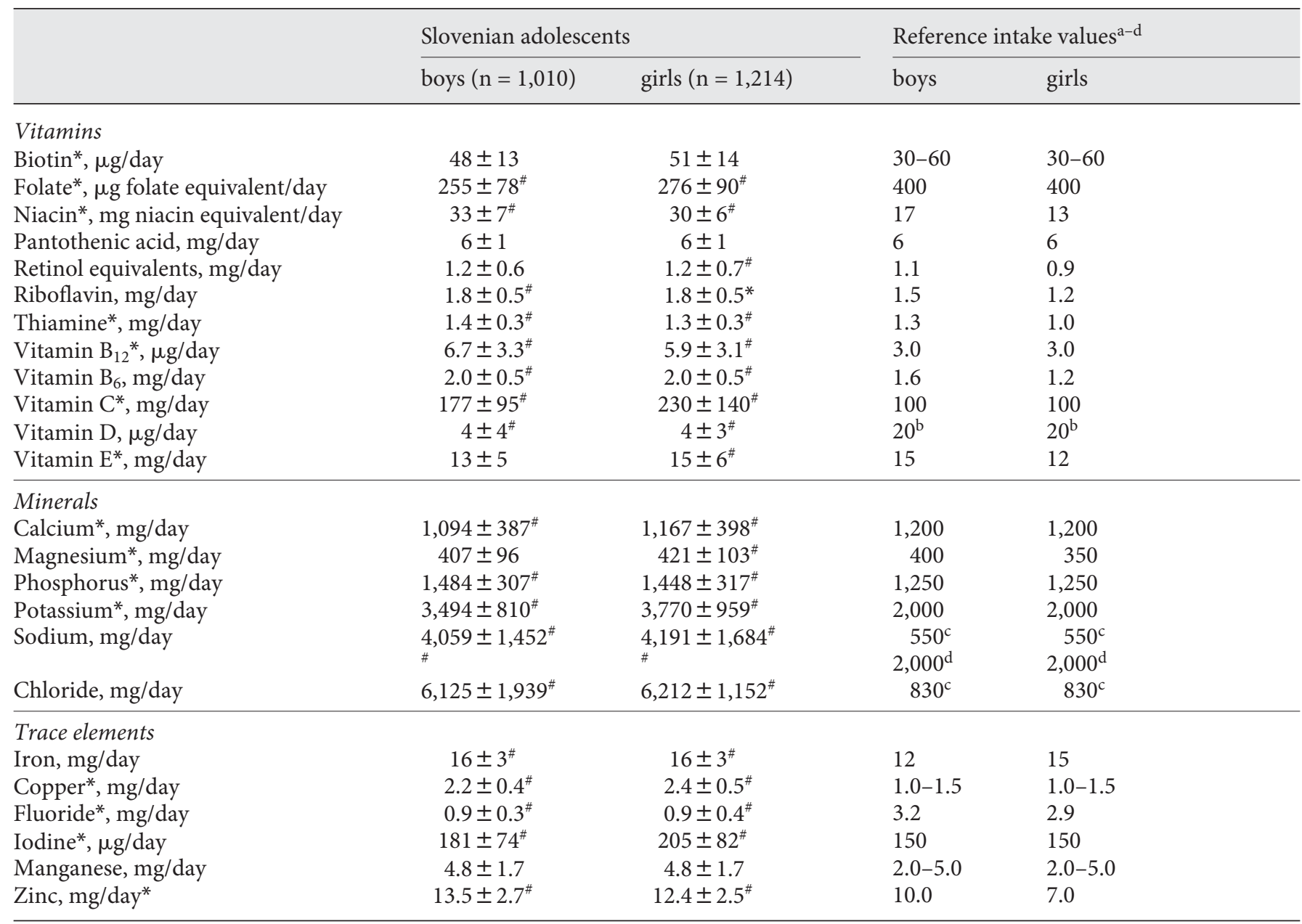

Values are means \pm SDs. ${ }^{*} \mathrm{p}<0.01$ between boys and girls; ${ }^{*} \mathrm{p}<0.05$ in comparison with the recommendations.

${ }^{a} \mathrm{D}-\mathrm{A}-\mathrm{CH}$ recommendations for the age group of 15 to $<19$ years; values for sexes are common or separated [10].

b New reference value for vitamin D [33].

${ }^{\mathrm{c}}$ Lower recommended amount according to D-A-CH recommendations [10].

${ }^{\mathrm{d}}$ Upper allowed amount according to WHO/FAO recommendations; corresponds to $<5 \mathrm{~g} \mathrm{NaCl} / \mathrm{day}, \mathrm{NaCl}(\mathrm{g})=\mathrm{Na}(\mathrm{g}) \times 2.54[41]$.

\section{Discussion}

This is the first study on the dietary habits of Slovenian adolescents. In this secondary data analysis, we used data obtained in the survey of goiter prevalence and the food intake of Slovenian adolescents $[4,5]$. We calculated the dietary intake using the FFQ in a representative sample of adolescents and determined portion sizes using the 3DP in a subgroup. The dietary habits of Slovenian adolescents are less than optimal. They consume an inappropriate composition of fat, excessive amounts of free sug- ars, especially in liquid form, and sodium, and belowreference intake values of some vitamins and minerals.

The strength of our study is the large number of participants ( $10 \%$ of adolescents entering high school) from all geographic regions of Slovenia and all sociodemographic backgrounds. An additional strength is the high participation rate $(95 \%$ of those invited), which was achieved firstly by inviting adolescents at the most appropriate time, while waiting for a medical examination, and secondly due to the invitation and high motivation for participation on the part of specially trained nurses, and 
Table 3. Intake of food groups of Slovenian adolescents aged $15-16$ years $(n=2,224)$ compared to the optimized mixed diet (adolescents aged 15-18 years) [29] (adapted from Kobe et al. [5])

\begin{tabular}{|c|c|c|c|c|c|c|}
\hline \multirow[t]{2}{*}{ Food amounts, g/day } & \multicolumn{4}{|c|}{ Diet of Slovenian adolescents } & \multicolumn{2}{|c|}{ Optimized mixed diet } \\
\hline & mean & SEM & mean & SEM & boys & girls \\
\hline \multicolumn{7}{|l|}{ Beverages and plant foods } \\
\hline Beverages & 1,549 & 29 & $1,750^{*}$ & 28 & 1,500 & 1,400 \\
\hline Vegetables & $179^{*}$ & 5 & $163^{*}$ & 4 & 350 & 300 \\
\hline Bread/cereals ${ }^{\mathrm{a}}$ & $271^{*}$ & 4 & $226^{*}$ & 4 & 350 & 280 \\
\hline Potatoes/rice/pasta & $212^{*}$ & 4 & $163^{*}$ & 3 & 280 & 230 \\
\hline \multicolumn{7}{|l|}{ Animal foods } \\
\hline Milk/milk products ${ }^{\mathrm{b}}$ & 513 & 10 & 479 & 9 & 500 & 450 \\
\hline Meat/meat products & $126^{*}$ & 3 & 85 & 2 & 85 & 75 \\
\hline Eggs & $5^{\mathrm{c}}$ & & $8^{\mathrm{c}}$ & & $20^{\mathrm{d}}$ & $20^{\mathrm{d}}$ \\
\hline
\end{tabular}

Food intakes are adjusted for energy intake. ${ }^{*} \mathrm{p}<0.001$ mean values were significantly different from the optimized mixed diet (Wilcoxon's signed-rank test).

${ }^{a}$ Cooked cereals including millet and wheat; legumes.

b Milk equivalents: $100 \mathrm{ml}$ milk corresponds to $15 \mathrm{~g}$ hard cheese or $30 \mathrm{~g}$ soft cheese.

${ }^{c}$ Data obtained from the 3DP, does not include eggs in other foods (e.g. pasta, pastry).

d Corresponds to 2-3 eggs/week.

${ }^{\text {e }}$ Fish only (i.e. without fish products), corresponds to 1 portion $(100-200$ g)/week.

${ }^{\mathrm{f}}$ E.g. sugar, sweets, jam, chocolate, cake.

thirdly because the FFQ could be completed within 15 min. Nevertheless, our results need to be interpreted with caution. We used a semi-quantitative method to assess dietary habits during the last year, so some degree of misestimation cannot be excluded. Since there is no representative database on food composition in Slovenia, we used a German database, which is the most widely used in Slovenia.

Based on the FFQ, the estimated energy intake of boys and girls (mean 3,043 and 2,312 kcal/day) was below the $\mathrm{D}$-A-CH reference values $(3,100$ and $2,500 \mathrm{kcal} /$ day for moderate physical activity) [10]. Slovenian adolescents probably do not, on average, achieve this activity level. In view of normal BMI, some degree of underreporting cannot be excluded. The $\mathrm{D}-\mathrm{A}-\mathrm{CH}$ reference values for energy intake (i.e. guiding values) are set at the level of the average energy requirement without a safety margin to avoid the risk of inadequate energy intake. This was chosen due to the fact that the problem of overweight in Germany, Austria, and Switzerland is higher than an insufficient energy intake [10]. The same concept was also adopted for Slovenia [11].

In boys there were no significant correlations between body weight or BMI and intakes of energy and macronutrients. A very weak negative correlation existed between body weight as well as BMI and energy intake in girls.

Observing adolescents according to 4 categories of BMI (underweight, healthful weight, overweight, and obese), underweight adolescents reported a lower energy intake than overweight and obese adolescents. However, some misreporting has to be considered: $34 \%$ of boys and $27 \%$ of girls underreported their energy intake, whereas $10 \%$ of boys and $11 \%$ of girls overreported their energy intake. Among underreporters, there were the lowest proportions of underweight and normal-weight adolescents but the highest proportions of overweight and obese adolescents. We investigated the misreporting of energy intake in adolescents. Excluding the misreporters (underand overreporters) would cause a loss of subjects but would not affect the mean energy values. Additionally, 
the exclusion would not be based on actual physical activity, since we did not investigate it [14]. To minimize the effect of misreporting of energy intake, we used statistical weighting to standardize the results and the residual method to adjust the nutrient intake for energy intake.

Studies on the dietary intake of adolescents of the same age in other countries similarly reported a low energy intake, i.e. 2,754 and 2,024 kcal/day for boys and girls, respectively, in Switzerland [15], 2,565 and 1,979 $\mathrm{kcal} /$ day in Spain [16], and 1,964 and 1,804 kcal/day in Turkey [17], although these comparisons should be made with caution due to different survey methods. SD for the total energy intake estimated from FFQs were found to be greater than those from dietary records [6].

Slovenian adolescents consumed a low percentage of energy from fat (28 and 29\%) but a high percentage from carbohydrates (57 and 58\%). A low percentage of energy from fat (30-33\%) was also found in Portuguese adolescents [18]. The proportions of energy from SFA, MUFA, and PUFA in the nutrition of Slovenian adolescents were: 13,10 , and $5 \%$ (in boys), and $6 \%$ (in girls), showing that they consumed too much SFA, mainly of animal origin (milk and milk products, meat and meat products), and too little PUFA, which are mainly found in plant oils and sea fish. A further indicator of an inappropriate fat composition was a low polyunsaturated/saturated fat ratio, which was 0.48 . A low polyunsaturated/saturated fat ratio was also found among adolescents from Western European countries [19] and among Turkish adolescents [17]. Several authors [20-22] have reported that Spanish adolescents have a high fat intake (39-45\% of energy), while the percentage of energy from MUFA is also high (18$19 \%)$, mainly due to a high consumption of olive oil.

The high contribution of carbohydrates to energy intake in Slovenian adolescents was due to the high intake of free sugars, which exceeded the WHO/FAO upper recommended limit [9] by $60 \%$ in boys and by $70 \%$ in girls (equal to 16 and $17 \%$ of the daily energy intake). Sugarsweetened beverages (i.e. fruit nectars, syrup beverages, sweetened tea, ice tea, and sweetened carbonated beverages) contributed 9 and 10\% to the daily energy intake of Slovenian adolescent boys and girls [5]. In a recent WHO report, Slovenian 15-year-old adolescents were at the top of 39 countries from Europe and North America in terms of the frequency of adolescents reporting drinking sugared soft drinks on at least a daily basis. This is a risk factor for increased energy intake, weight gain, overweight and obesity, metabolic syndrome, and diabetes type 2 [23]. Different definitions of sugars have been used in different studies. German children and adolescents consumed 13\% of energy from added sugars, which were defined as all refined sugars eaten separately at the table or used as ingredients in processed or prepared foods [24]. In our study, added sugar intake, according to this definition, was $11 \%$ of the energy. In one survey in Spain, added sugars contributed $16 \%$ of the energy in adolescents [18]. Adolescents should reduce their intake of industrially prepared foods that are rich in sugar, especially sugar-sweetened beverages and confectionary. A high-sugar content was found to contribute significantly to the total caloric intake, but it does not satisfy nutrient requirements [24, 25]. Sugar-sweetened beverages are a significant contributor to energy intake. Water should be promoted as the main source of fluids. Limiting the supply of rapidly absorbed carbohydrates and simple sugars should be promoted, with a preferential intake of slowly absorbed carbohydrates [26].

The boys in our study had a sufficient fiber intake, while the girls' absolute intake was adequate but had too low a fiber density. A low dietary fiber intake was also reported among adolescents in Germany [27] and Denmark [28].

Slovenian adolescents consumed too low amounts of folate. Folate is mainly found in vegetables, whole grains, beans, and breakfast cereals [8], all of which are consumed in too low quantities by Slovenian adolescents (table 3). As noted previously, only $11 \%$ of Slovenian adolescent boys and $10 \%$ of girls in our study consumed the recommended amount of vegetables (boys on average 179 $\mathrm{g} /$ day vs. recommended $350 \mathrm{~g} /$ day [29]; girls on average $163 \mathrm{~g} /$ day vs. recommended $300 \mathrm{~g} /$ day [29]). The consumption of too low amounts of folate was also reported for Spanish and Turkish adolescents [16, 17]. Inadequate folate intake in childhood and adolescence has been correlated with elevated plasma levels of homocysteine, which may be a risk factor for cardiovascular diseases later in life [30]. A study in Germany demonstrated that folic and pantothenic acid supplements help to achieve a higher proportion of recommendations in some age groups and especially in girls [31].

Slovenian adolescents had a dietary intake of vitamin $\mathrm{D}$ of $4 \mu \mathrm{g}$, which is similar to that of adolescents in Germany [32]. In the absence of endogenous synthesis, this quantity is insufficient to reach the estimated value of adequate vitamin $\mathrm{D}$ intake that ensures the desired $25(\mathrm{OH}) \mathrm{D}$ serum concentration of at least $50 \mathrm{nmol} / \mathrm{l}$. The difference between dietary vitamin D intake through habitual diet and the reference intake value much be covered by endogenous synthesis and/or an additional intake of vitamin D [33]. Too low amounts of vitamin D and cal- 
cium, which were also reported for adolescents in Austria, indicate a high risk of the development of bone metabolism disorders [34]. Especially in girls, an inadequate intake of calcium during the years of achieving peak bone mass may lead to osteoporosis later in life [35].

The fluoride intake in Slovenian adolescents was also considerably below the recommendations (1.0 and 0.9 $\mathrm{mg} /$ day for boys and girls, respectively). Even lower levels were found in German children (0.1-0.3 mg/day) [36].

The WHO/FAO recommendation is $<2$ g sodium intake per day [9]. Slovenian adolescents had a sodium intake that was $107 \%$ above the upper limit (i.e. $207 \%$ of the WHO/FAO recommendation), which shows that the salt intake was markedly too high.

The dietary habits of Slovenian adolescents show patterns with potential risks of cardiovascular diseases, in terms of several indicators. Firstly, too high an intake of SFA increases the level of LDL cholesterol in plasma [37]. Secondly, a high intake of mono- and disaccharides is thought to reduce the level of plasma HDL cholesterol [38]. This causes a raised LDL/HDL ratio, which plays an important role as a risk factor for coronary heart diseases [39]. Furthermore, the high intake of sodium found among adolescents in our study clearly indicates an excessive salt intake, which is related to high blood pressure [40]. Multiple observational studies have shown a clear association of sodium consumption with cardiovascular disease, as well as gastric cancer, osteoporosis, cataracts, kidney stones, and diabetes [41]. Cardiovascular diseases are the leading cause of death in Slovenia ( $40 \%$ of all deaths) [42].

A major limitation of our study is that we had no resources for designing and validating a questionnaire de novo. We used an existing, evaluated semiquantitative questionnaire, as purposed by Willett [6]. The Harvard University FFQ is the most widely used FFQ in epidemiological studies. It covers all of the main foods eaten also in Slovenia. Some traditional Slovenian foods represent only a very minor intake in most Slovenain adolescents. Since the questionnaire was semiquantitative, developed for the US population, and, prior to the study, not evaluated in Slovenian adolescents, the results must be interpreted with caution. Willett [6] reported that the portion size specification for foods without natural units was sometimes ignored by participants who complete the FFQ. The marked frequency of consumption in the FFQ would therefore have been the same even if the portion size was different. In order to check this, we compared the portion sizes from the FFQ to those calculated from the $3 \mathrm{DP}$, separately for boys and girls, in a subgroup $(\mathrm{n}=180)$ [those that completed both the FFQ $(n=2,224)$ and the
3DP $(n=191)$ correctly]. We found that the portion size specification for foods without natural units was ignored by adolescents. For evaluation of the FFQ, therefore, we used the average portion sizes of foods without natural units obtained from the 3DP for boys and girls separately. Ideally, the subgroup of adolescents with 3DP would be even larger. A further limitation of our study is that we did not provide standard digital scales to adolescents to weigh their food intake. Some degree of misreporting, including underreporting, cannot therefore be excluded.

In conclusion, as in other countries, our first national study on the dietary intake of Slovenian adolescents also indicates their less-than-optimal dietary habits. Since nutrition that provides an adequate nutrient intake in adolescence is of crucial importance for health later in life, action should be taken to improve the nutrition of adolescents.

\section{Acknowledgements}

We would like to express our gratitude to Ciril Kržišnik, Primož Kotnik, Mihaela Jurčec, Andreja Širca-Čampa, and Damjana Podkrajšek for help in organizing and coordinating this study. Many thanks also go to all of the pediatricians and nurses. We would also like to thank Janez Stare from the Institute of Biomedical Informatics, Medical Faculty, University of Ljubljana, for assistance with statistical analysis, as well as Eric L. Ding from Harvard Medical School and Brigham and Women's Hospital for assistance in writing the manuscript. Last but not least, we would like to thank all of the participating adolescents.

This study was supported by the Ministry of Science and Technology, Ljubljana, Slovenia (project No. J3-4512), and the Ministry of Health, Ljubljana, Slovenia (project No. C2711-08Y000178).

References

1 Story M, Neumark-Sztainer D, French S: Individual and environmental influences on adolescent eating behaviors. J Am Diet Assoc 2002;102:S40-S51.

2 Jenkins S, Horner SD: Barriers that influence eating behaviors in adolescents. J Pediatr Nurs 2005;20:258-267.

-3 Livingstone MB, Robson PJ: Measurement of dietary intake in children. Proc Nutr Soc 2000;59:279-293.

-4 Kotnik P, Širca-Čampa A, Zupančič M, Štimec M, Smole K, Fidler Mis N, et al: Goiter prevalence and urinary iodine concentration in Slovenian adolescents. Thyroid 2006;16: 769-773.

5 Kobe H, Štimec M, Ribič CH, Fidler Mis N Food intake in Slovenian adolescents and adherence to the optimized mixed diet: a nationally representative study. Public Health Nutr 2012;15:600-608. 
6 Willett W: Nutritional Epidemiology, ed 2. Oxford, Oxford University Press, 1998.

7 Thompson FE, Byers T: Dietary assessment resource manual. J Nutr 1994;124(suppl 11):2245S-2317S.

8 Nutri-Science: Prodi 5.2 (computer program). Stuttgart, Wissenschaftliche Verlagsgesellschaft Stuttgart, 2004.

9 WHO: Diet, nutrition and the prevention of chronic diseases - joint WHO/FAO expert consultation. WHO Technical Report Series 916. Geneva, WHO, 2003.

10 German Nutrition Society, Austrian Nutrition Society, Society for Nutrition Research, Swiss Nutrition Association: Referenzwerte für die Nährstoffzufuhr, ed 1. Frankfurt am Main, Umschau Braus, 2008.

11 German Nutrition Society, Austrian Nutrition Society, Society for Nutrition Research, Swiss Nutrition Association: Referenčne vrednosti za vnos hranil, ed 1. Ljubljana, Ministrstvo za zdravje, 2004.

12 Willett WC, Stampfer MJ: Total energy intake: implications for epidemiologic analyses. Am J Epidemiol 1986;124, 17-27.

13 Statistical Office of the Republic of Slovenia, Ministry of the Interior, Census of population, Ministry of the Interior, Internal Administrative Affairs Directorate, 2005.

14 Kobe H, Kržišnik C, Mis NF: Under- and over-reporting of energy intake in Slovenian adolescents. J Nutr Educ Behav 2011, E-pub ahead of print.

15 Clavien H, Theintz G, Rizzoli R, Bonjour JP: Does puberty alter dietary habits in adolescents living in a Western society? J Adolesc Health 1996;19:68-75.

-16 Serra-Majem L, Ribas-Barba L, Perez-Rodrigo C, Bartrina JA: Nutrient adequacy in Spanish children and adolescents. Br J Nutr 2006;96(suppl 1):S49-S57.

- 17 Bas M, Altan T, Dincer D, Aran E, Kaya HG, Yuksek O: Determination of dietary habits as a risk factor of cardiovascular heart disease in Turkish adolescents. Eur J Nutr 2005;44: 174-182.

18 Cruz JA: Dietary habits and nutritional status in adolescents over Europe-Southern Europe. Eur J Clin Nutr 2000;54(suppl 1):S29S35.

19 Rolland-Cachera MF, Bellisle F, Deheeger M: Nutritional status and food intake in adolescents living in Western Europe. Eur J Clin Nutr 2000;54(suppl 1):S41-S46.

20 Failde I, Zafra JA, Ruiz E, Novalbos JP: Evaluation of nutrition of school children in the population of Sierra de Cadiz (Ubrique). Med Clin (Barc) 1997;108:254-258.
21 Salas J, Font I, Canals J, Fernandez-Ballart J, Marti-Henneberg C: Consumption, food habits and nutritional status of the Reus population. 5. Energy and immediate principles. Med Clin (Barc) 1987;88:363-368.

22 Vazquez C, de Cos AI, Martinez P, Jaunsolo MA, Roman E, Gomez C, et al: Nutrient and food consumption by ages and gender in school children from the community of $\mathrm{Ma}$ drid (CAENPE). Rev Clin Esp 1996;196:501508.

23 Barnekow V, Currie C, Currie D, de Looze M, Morgan A, Roberts C, Samdal O, Smith OR, Zanotti C: Social Determinants of Health and Well-Being among Young People Health Behaviour in School-Aged Children (HSBC) Study: International Report from the 2009/2010 Survey. Health Policy for Children and Adolescents, No. 6. Copenhagen, WHO, 2012, p 115-121.

24 Alexy U, Sichert-Hellert W, Kersting M: Associations between intake of added sugars and intakes of nutrients and food groups in the diets of German children and adolescents. Br J Nutr 2003;90:441-447.

25 Overby NC, Lillegaard IT, Johansson L, Andersen LF: High intake of added sugar among Norwegian children and adolescents. Public Health Nutr 2004;7:285-293.

26 ESPGHAN Committee on Nutrition, Agostoni C, Braegger C, Decsi T, Kolacek S, Koletzko B, Mihatsch W, Moreno LA, Puntis J, Shamir R, Szajewska H, Turck D, van Goudoever J: Role of dietary factors and food habits in the development of childhood obesity: a commentary by the ESPGHAN Committee on Nutrition. J Pediatr Gastroenterol Nutr 2011;52:662-669.

27 Kersting M, Sichert-Hellert W, Alexy U, Manz F, Schoch G: Macronutrient intake of 1 to 18 year old German children and adolescents. Z Ernahrungswiss 1998;37:252-259.

28 Biltoft-Jensen A, Trolle E, Christensen T, Ygil KH, Fagt S, Matthiessen J, et al: Development of a recommended food intake pattern for healthy Danish adolescents consistent with the Danish dietary guidelines, nutrient recommendations and national food preferences. J Hum Nutr Diet 2008;21:451463.

29 Kersting M, Alexy U, Clausen K: Using the concept of food based dietary guidelines to develop an Optimized Mixed Diet (OMD) for German children and adolescents. J Pediatr Gastroenterol Nutr 2005;40:301-308.
30 Lutsey PL, Steffen LM, Feldman HA, Hoelscher DH, Webber LS, Luepker RV, et al: Serum homocysteine is related to food intake in adolescents: the Child and Adolescent Trial for Cardiovascular Health. Am J Clin Nutr 2006;83:1380-1386.

31 Sichert-Hellert W, Wenz G, Kersting M: Vitamin intakes from supplements and fortified food in German children and adolescents: results from the DONALD study. J Nutr 2006;136:1329-1333.

32 Max Rubner-Institut: Nationale Verzehrsstudie II, Ergebnisbericht Teil 2. Karlsruhe, Max Rubner-Institut, 2008.

33 New reference values for vitamin D. Ann Nutr Metab 2012;60:241-246.

34 Koenig J, Elmadfa I: Status of calcium and vitamin $\mathrm{D}$ of different population groups in Austria. Int J Vitam Nutr Res 2000;70:214220

35 Schettler AE, Gustafson EM: Osteoporosis prevention starts in adolescence. J Am Acad Nurse Pract 2004;16:274-282.

- 36 Bergmann KE, Bergmann RL: Salt fluoridation and general health. Adv Dent Res 1995; 9:138-143

37 Expert Panel on Detection Evaluation and Treatment of High Blood Cholesterol in Adults: Executive summary of the third report of the National Cholesterol Education Program (NCEP) Expert Panel on Detection, Evaluation and Treatment of High Blood Cholesterol in Adults (Adult Treatment Panel III). JAMA 2001;285:2486-2497.

- 38 Starc TJ, Shea S, Cohn LC, Mosca L, Gersony WM, Deckelbaum RJ: Greater dietary intake of simple carbohydrate is associated with lower concentrations of high-density-lipoprotein cholesterol in hypercholesterolemic children. Am J Clin Nutr 1998;67:11471154.

39 Kinosian B, Glick H, Garland G: Cholesterol and coronary heart disease: predicting risks by levels and ratios. Ann Intern Med 1994, 121:641-647.

- 40 He FJ, Marrero NM, MacGregor GA: Salt and blood pressure in children and adolescents. J Hum Hypertens 2008;22:4-11.

41 WHO: Reducing salt intake in populations: report of a WHO forum and technical meeting. Geneva, WHO, 2006.

42 Maučec Zakotnik J, Hlastan Ribič C, Poličnik R, Štern B, Pokorn D, Ministry of Health: Resolucija o nacionalnem programu prehranske politike 2005-2010. http://www. uradni-list.si/1/objava.jsp? urlid=200539 \&stevilka=1392 (accessed March 2012). 